\title{
Estradiol inhibits vascular endothelial cells pro-inflammatory activation induced by $\mathrm{C}$-reactive protein
}

\author{
Émilie Cossette $\cdot$ Isabelle Cloutier $\cdot$ Kim Tardif • \\ Geneviève DonPierre $\cdot$ Jean-François Tanguay
}

Received: 17 May 2012/ Accepted: 17 October 2012/Published online: 31 October 2012

(C) The Author(s) 2012. This article is published with open access at Springerlink.com

\begin{abstract}
In addition of being an important inflammatory biomarker and a risk factor for cardiovascular disease, much evidence indicates that the C-reactive protein (CRP) contributes to the atherosclerosis development process. This plasmatic protein synthesized by hepatocytes in response to inflammation and tissue injury induces proinflammatory molecules' expression by endothelial cells (ECs). Previous studies showed that the $17 \beta$-estradiol (E2) has beneficial effects on vascular cells by reducing in vitro pro-inflammatory molecules expressions in EC. Therefore, we hypothesize that E2 blocks or reduces CRP-mediated inflammatory responses by modulating endogenous production of CRP in EC and/or activation mechanisms. Using human aortic ECs (HAECs), we first evaluated CRP production by vascular EC and second demonstrated its selfinduction. Indeed, recombinant human CRP stimulation induces a fivefold increase of CRP expression. A 1-h pretreatment of E2 at a physiologic dose $\left(10^{-9} \mathrm{M}\right)$ leads to an important decrease of CRP production suggesting a partial blockage of its amplification loop mechanism. Furthermore, in HAEC, E2 reduces the secretion of the most potent agonist of CRP induction, the IL-6, by $21 \%$. E2 pre-treatment also decreased the expression of proinflammatory molecules IL-8, VCAM-1, and ICAM-1 induced by CRP and involved in leukocytes recruitment. In
\end{abstract}

É. Cossette · I. Cloutier · K. Tardif · G. DonPierre .

J.-F. Tanguay $(\square)$

Research Center, Montreal Heart Institute, 5000 Bélanger Street, Montreal, QC H1T 1C8, Canada

e-mail: jean-francois.tanguay@icm-mhi.org

É. Cossette - K. Tardif - G. DonPierre - J.-F. Tanguay

Département de Sciences Biomédicales, Faculté de Médecine,

Université de Montréal, 2900 Blvd Édouard-Montpetit,

Montreal, QC H3T 1J4, Canada addition, we demonstrated that E2 could restore vascular endothelial growth factor-mediated EC migration response impaired by CRP suggesting another pro-angiogenic property of this hormone. These findings suggest that E2 can interfere with CRP pro-inflammatory effects via activation signals using its rapid, non-genomic pathway that may provide a new mechanism to improve vascular repair.

Keywords C-reactive protein - Estradiol .

Atherosclerosis · Inflammation · Endothelial cells

\section{Introduction}

Cardiovascular disease (CVD) is currently the most important cause of death in developed countries. Atherosclerosis, the underlying cause of most CVDs, is a dynamic and progressive inflammatory disease characterized by lipid plaque formation within the arterial wall and luminal reduction. In fact, accumulating data suggest that the inflammatory process plays a central role in the initiation, progression, and the final steps of this pathology as vulnerable plaque rupture $[1,2]$. Many risk factors have been associated with the development of atherosclerosis such as age, hypercholesterolemia, male sex, diabetes, obesity, and hypertension [3-6]. As atherosclerosis represents a process of chronic vascular inflammation, investigations have confirmed inflammatory biomarkers as new risk factors. Various plasmatic inflammatory markers are now considered to identify patients with higher risk of future CVD [7]. However, the C-reactive protein (CRP) has emerged as the most powerful predictor and is an extensively studied systemic marker of inflammation [8]. In fact, among other systemic inflammatory mediators, CRP has been widely accepted as a strong and independent risk factor predicting 
CVD [9]. As so, elevated baseline concentration of high sensitive CRP (hsCRP) correlates with the risk of future atherosclerotic events $[10,11]$.

CRP, composed of five identical associated and nonglycosylated $23-\mathrm{kDa}$ subunits, is an acute phase reactant induced during inflammation reaching up to 100 - to 1,000 fold its baseline plasma concentration in 24-72 h [12]. Synthesized mainly in the liver by hepatocytes in response to inflammation and tissue injury, it was detected in atherosclerotic lesions and coronary artery walls [13]. More recently, it was demonstrated to be secreted by other cell types such as smooth muscle cells (SMCs), macrophages, and endothelial cells (ECs) [14-16]. Initially considered as an inflammatory biomarker of CVD, evidence now suggests that CRP may also participate in all processes of atherogenesis from endothelial dysfunction to plaque rupture [17]. Indeed, CRP has been implicated in reducing mediators of vasodilatation such as nitric oxide (NO) [18], inducing expression of pro-inflammatory molecules by EC $[19,20]$ and promoting recruitment of leukocytes to vascular lesions [21]. CRP may contribute to lipid content in forming plaques by aggregating low density-lipoprotein (LDL) molecules which upon excessive uptake by macrophages will favor foam cell development [22]. CRP promotes vascular SMC proliferation and migration [23] while slowing down the reendothelialization process by reducing the vascular endothelial growth factor (VEGF)-mediated migratory response of EC after vascular injury [24]. Therefore, CRP may be an important therapeutic target for the prevention and treatment of atherosclerosis.

Women develop coronary heart diseases on an average of 10 years later than men. This has been attributed, at least in part, to the protective effects of female sex hormones, particularly estrogens $[25,26]$. In fact, this effect is lost after menopause when the concentration of $17 \beta$-estradiol (E2) is reduced drastically [27]. Several studies have shown that E2 has vasoprotective effects and can modulate inflammatory responses [26, 28]. One of its mechanisms of action in cardiovascular protection consists in improving lipid profile by increasing high density-lipoprotein-cholesterol, while lowering LDL-cholesterol [29]. E2 also promotes arterial vasorelaxation and inhibits platelet aggregation by regulating NO bioavailability [30]. Another important role in vasoprotection is to accelerate reendothelialization and repair after vascular injury. We have shown that intravascular delivery of E2 before stent implantation improves vascular healing with accelerated reendothelialization and inhibition of the inflammatory response, reducing in-stent restenosis $[31,32]$. E2 also regulates a variety of anti-inflammatory properties such as reducing vascular expression of chemokines, cytokines, and adhesion molecules, therefore decreasing leukocyte recruitment and accumulation into the vascular wall $[33,34]$.
However, despite the possible role of CRP in atherogenesis, little is dedicated to the investigation of possible therapeutic strategies to reduce its concentration in the atherosclerotic site. In this study, we hypothesized that E2 blocks or reduces CRP-mediated inflammatory response by modulating endogenous production of CRP in EC and/or activation mechanisms. The current study is the first to underline the capacity of E2 pre-treatment to decrease the CRP autoinduction and triggered ILs- 6 and -8 cytokines secretion, key players in the inflammatory process. E2 pretreatment reduces expression of adhesion molecules, VCAM-1 and ICAM-1, induced by CRP. In addition, we assessed the ability of E2 to counteract impairment of EC migration by CRP. As we suggested, E2 partially restored VEGF-promoted migration of CRP-treated EC.

\section{Materials and methods}

\section{Reagents}

Recombinant human CRP (rhCRP) (Lee Biosolutions, St. Louis, MN, USA) was dialyzed for $24 \mathrm{~h}$ using a dialysis slide (Fisher Scientific, Ottawa, CAN) with a cutoff of 10 $\mathrm{kDa}$ to remove sodium azide from commercial CRP preparations. In a second step, the CRP was purified using a Detoxigel column (Fisher Scientific) to remove contaminating lipopolysaccharide (LPS), and the absence of endotoxin was confirmed by a limulus amebocyte lysate test (LONZA, Walkersvelle, MD). Water soluble 17ß-estradiol and LPS from Escherichia coli 0111:B4 were obtained from Sigma Aldrich (St. Louis, USA). Enzymelinked immunosorbent assay (ELISA) kit OptEIA for the measurement of ILs- 6 and -8 are from BD Biosciences (Mississauga, ON, CA). NG-nitro-L-arginine-methyl ester hydrochloride (L-NAME.HCL) was purchased from Enzo Life Sciences (Farmingdale, NY, USA). Recombinant human VEGF $_{165}$ and human VEGF ELISA development kits were provided from Peprotech (Rocky Hill, NJ, USA), while (S)-nitroso- $N$-acetylpenicillamine was from Tocris Bioscience (Ellisville, Missouri, USA). Monoclonal antihuman/mouse/porcine CRP antibody, monoclonal antihuman VEGF receptor-2 (VEGFR-2)/KDR-phycoerythrin $(\mathrm{PE})$, and mouse IgG1 PE isotype control were purchased from R \& D systems (Minneapolis, MN, USA). The antiactin (I-19) antibody, goat anti-mouse IgG-HRP, and donkey anti-goat IgG-HRP were obtained from Santa Cruz Biotechnology (Santa Cruz, CA, USA).

\section{Cell culture}

Human aortic EC (HAEC) were purchased from LONZA and used in experiments at passages 4-6. Cells were 
cultured with EGM-2MV BulletKit (LONZA) supplemented with $5 \%$ FBS, $0.6 \%$ HEPES, and maintained at $37{ }^{\circ} \mathrm{C}$ in a $5 \% \mathrm{CO}_{2}$ humidified incubator. All FBS used were pre-treated with $1 \%$ charcoal to eliminate endogenous estrogens. For this, charcoal was added to FBS, gently mixed for $1 \mathrm{~h}$ at room temperature before filtration on a $0.22-\mu \mathrm{m}$ filter and stored at $4{ }^{\circ} \mathrm{C}$. HAEC were plated in sixwell plates (Costar, Corning, NY, USA) at $1.5 \times 10^{4}$ cells/ $\mathrm{cm}^{2}$ and cultured to 80-90\% confluence before being starved in EGM-2MV, $0.1 \%$ FBS for $18 \mathrm{~h}$ prior the different treatments.

Analysis of protein expression by western blot

To evaluate the self-induction of CRP and adhesion molecules (VCAM-1 and ICAM-1) protein expression, HAECs were first treated with rhCRP at different doses $(1,2.5,5,10$ and $25 \mu \mathrm{g} / \mathrm{ml}$ ) for $24 \mathrm{~h}$. To evaluate the impact of estrogen on these inductions, cells were pre-treated with E2 $\left(10^{-8}\right.$ or $\left.10^{-9} \mathrm{M}\right)$ for $1 \mathrm{~h}$ before being exposed to rhCRP at $25 \mu \mathrm{g} / \mathrm{ml}$ for $24 \mathrm{~h}$. Single treatments were used as reference controls. After the incubation period, cells were lysed using lysis buffer (20 mM Tris- $\mathrm{HCl}, 150 \mathrm{mM} \mathrm{NaCl}, 1.2 \%$ Triton X-100, $1 \mathrm{mM}$ EGTA, $1 \mathrm{mM}$ EDTA, $1 \mathrm{mM}$ PMSF, $15.1 \mu \mathrm{l} / \mathrm{ml}$ aprotinine, $10 \mu \mathrm{g} / \mathrm{ml}$ leupeptin, and $1 \mathrm{mM} \mathrm{NaVO}_{3}$ ). Total protein extract was quantified by Bradford technique (Bio-Rad). Equivalent amount of protein $(20 \mu \mathrm{g})$ was migrated on a $15 \%$ sodium dodecyl sulfate gel (SDS-PAGE). rhCRP (5 ng) was added to SDS-PAGE as positive control. Proteins were transblotted to a polyvinylidene difluoride membrane that was soaked in $5 \%$ non-fat dry milk prepared in TBS-T [Trisbuffered saline (63 mM Tris- $\mathrm{HCl}, 7.3 \mathrm{mM} \mathrm{NaCl}$ ) containing $0.1 \%$ Tween 20] for $1 \mathrm{~h}$ at room temperature to block nonspecific binding. Membranes were then incubated overnight with one of the following primary antibodies: anti-CRP (1/ 500), anti-actin I-19 (1/1,000), anti-VCAM-1(1/1,000), and anti-ICAM-1 $(1 / 2,000)$ antibodies. After three washes in TBS$\mathrm{T}$ at room temperature, membranes were incubated with a horseradish peroxidase-conjugated goat anti-mouse IgG (1/10 $000)$ or donkey anti-goat $\operatorname{IgG}(1 / 20000)$ or donkey anti-rabbit $\operatorname{IgG}(1 / 10000)$ for $1 \mathrm{~h}$ at room temperature. The blots were washed three times with TBS-T and antigen detection was performed using Immun-Star Western $\mathrm{C}$ kit (Bio-Rad). The band intensity was analysed by Quantity One program. Results are expressed in the ratio over actin.

\section{ELISA assay for ILs-6, -8 and VEGF}

Cytokines secretion by HAEC was evaluated after stimulation with rhCRP at $25 \mu \mathrm{g} / \mathrm{ml}$ for $24 \mathrm{~h}$ with or without a pre-treatment with E2 $\left(10^{-8}\right.$ or $\left.10^{-9} \mathrm{M}\right)$ for $1 \mathrm{~h}$. After the incubation period, supernatants were harvested and centrifuged to remove cells. ILs-6, -8, and VEGF concentrations in culture media were measured using commercially available ELISA kits. All procedures were performed according to the manufacturer's instructions. All samples were assessed in triplicate.

\section{Cellular migration assay}

HAEC migration mediated by VEGF was assessed in Transwell cell-culture 96 well plates (Corning) equipped with a gelatine-coated polycarbonate membrane with $5-\mu \mathrm{M}$ pores. Before the assay, cells were pre-treated in six-well plates with E2 $\left(10^{-8}\right.$ or $\left.10^{-9} \mathrm{M}\right)$ for $1 \mathrm{~h}$, stimulated with rhCRP at $25 \mu \mathrm{g} / \mathrm{ml}$ for $24 \mathrm{~h}$ or each treatment alone. L-NAME $\left(10^{-4} \mathrm{M}\right)$ was added for $30 \mathrm{~min}$ before the treatment of E2 and stimulation of rhCRP or the combination of both. Cells were harvested with trypsin-0.05\% EDTA for 2 min, resuspended in EGM-2MV, $1 \%$ FBS and $5 \times 10^{4}$ cells were added in the upper chamber of the Transwell plate and were migrated for $4 \mathrm{~h}$. EGM-2MV and $1 \% \mathrm{FBS}$ alone or with VEGF (20 ng/ml) was added to the lower chamber as chemoattractant. For inhibitors' study, L-NAME $\left(10^{-4} \mathrm{M}\right)$ was added to the upper and lower compartment and was present throughout the experiment. After $4 \mathrm{~h}$ incubation at $37{ }^{\circ} \mathrm{C}$ in the presence of $5 \% \mathrm{CO}_{2}$, the cells were fixed in methanol, stained with hematoxylin-eosin dye, and the top side of the insert membrane was scrubbed free of cells with a cotton swab. Membranes were removed using a scalpel and mounted on microscope slides with migrated cell face up. Three evenly spaced fields on each membrane were chosen and pictures were taken using an inverse light microscope (CKX41 of Olympus) equipped with a camera (QIMAGING, QICAM, Olympus) to obtain a computer-digitized image. Counts of migrated cells were performed by a person blinded to treatment by means of ImagePro 6.2 software. Each condition was tested at least in triplicate.

\section{VEGFR-2 expression using flow cytometer}

HAEC were pre-treated with E2 $\left(10^{-8}\right.$ or $\left.10^{-9} \mathrm{M}\right)$ for $1 \mathrm{~h}$, stimulated with rhCRP at $25 \mu \mathrm{g} / \mathrm{ml}$ for $24 \mathrm{~h}$ or each treatment alone to evaluate VEGFR-2 expression at the cell surface. Harvested cells were resuspended in PBS-0.5\% BSA and non-specific binding sites were blocked with $5 \%$ of normal mouse serum before 20-min incubation with monoclonal anti-human VEGFR-2/KDR-phycoerythrin (PE, $5 \mu \mathrm{g} / \mathrm{ml}$ ) or mouse IgG1 PE isotype control $(2.5 \mu \mathrm{g} / \mathrm{ml})$ for $20 \mathrm{~min}$. Cells were then washed with PBS$0.5 \%$ BSA and resuspended in cytometer buffer. System II software for XL/XLMCL flow cytometer was used for acquisition on an Epics XL coulter cytometer. For each sample, 10,000 cells were analyzed by the program Weasel. Data are expressed as mean fluorescence intensities 
(MFIs) after background subtraction from the corresponding IgG control.

Statistical analysis

All data were presented as mean \pm SEM. Statistical analyses were performed by one-way analysis of variance for multiple testing followed by Dunnett for ELISA, western blot, adhesion molecules analysis (VCAM-1 and ICAM-1) and EC migration assays, and by Tukey-Kramer multiple comparisons post-test for all other experiments. All statistics were performed by the GraphPad InStat software. Probability values were considered significant at $p<0.05$.

\section{Results}

Auto-induction of CRP production by HAECs

Self-induced CRP protein expression in vascular EC was investigated. There was no CRP protein detectable under basal (non-stimulated cells) condition. Incubation of HAECs with rhCRP enhanced the CRP protein level in a dose-dependent manner (Fig. 1). A fivefold increase in CRP self-induction was obtained with $25 \mu \mathrm{g} / \mathrm{ml}$ of rhCRP when compared to $10 \mu \mathrm{g} / \mathrm{ml}$. This increase was significant compared to all other rhCRP concentrations. The dose of $25 \mu \mathrm{g} / \mathrm{ml}$ was selected to conduct further investigation.

E2 inhibits the auto-induction of CRP by HAECs

To evaluate the capacity of E2 to reduce or block the CRP self-induction, cells were pre-treated with a supraphysiologic and physiologic doses $\left(10^{-8}\right.$ and $\left.10^{-9} \mathrm{M}\right)$ of E2 before the rhCRP stimulation. HAEC treated with E2 alone were still negative for CRP protein expression (Fig. 2). When added in pre-treatment before the CRP stimulation, E2 significantly inhibits the CRP self-induction with a $50 \%$ reduction at the physiologic dose of E2 in a dosedependent manner $\left(10^{-9} \mathrm{M}\right)(p<0.01)$.

E2 reduces CRP-induced pro-inflammatory cytokine response

As E2 pre-treatment reduces the CRP expression, we have investigated the impact of E2 on IL-6 secretion, one of the most potent agonists of CRP production [12]. In a doseresponse study, we first observed a significant increase in IL-6 secretion only with the $25 \mu \mathrm{g} / \mathrm{ml}$ of rhCRP (Fig. 3a). A twofold rise in IL- 6 release was observed between the 10 $\mu \mathrm{g} / \mathrm{ml}$ CRP dose and the highest dose. An E2 pre-treatment for $1 \mathrm{~h}$ at $10^{-9} \mathrm{M}$ reduced by $21 \%$ the IL-6 secretion triggered by the rhCRP stimulation (Fig. 3c).
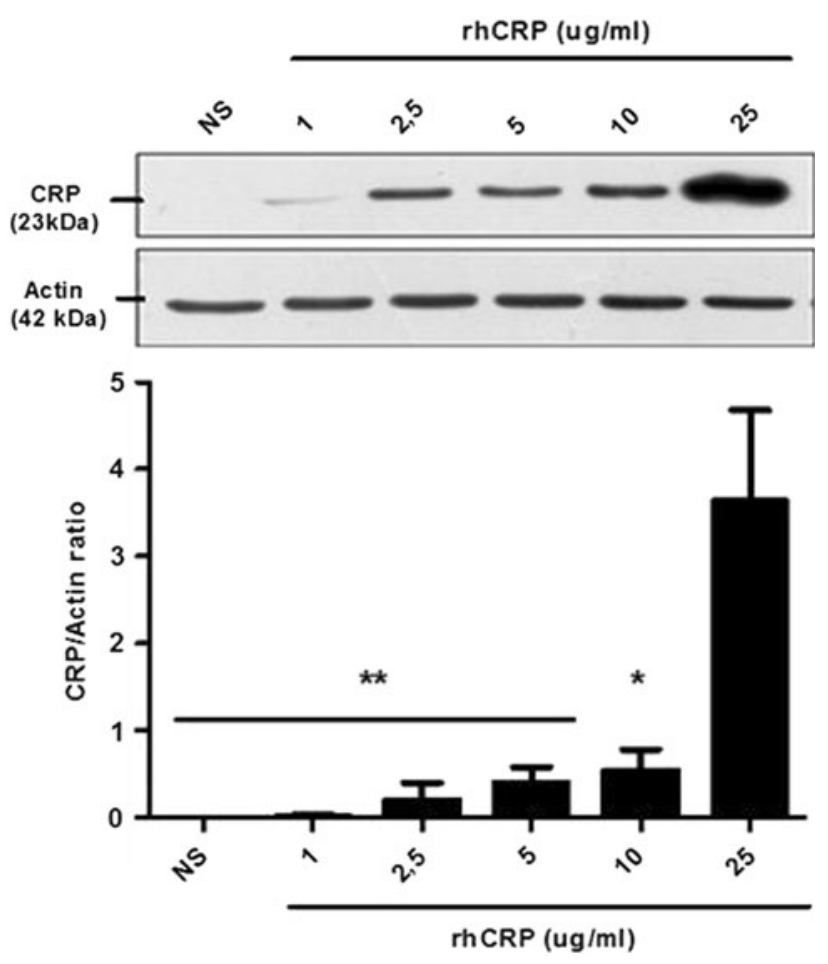

Fig. 1 CRP autoinduction in a dose-dependent manner. CRP protein expression was evaluated following HAEC treatment with increasing concentrations of rhCRP for $24 \mathrm{~h}$. CRP protein level was determined by western blot analysis and normalized to the level of $\beta$-actin protein. Data represent the mean $\pm \operatorname{SEM}(N=4)$. $* * p<0.001$ versus CRP $25 \mu \mathrm{g} / \mathrm{ml} ; *_{p}<0.01$ versus CRP $25 \mu \mathrm{g} / \mathrm{ml}$

We have extended our analysis to another cytokine- the IL-8, an important player of the inflammatory process promoting leukocyte recruitment and adhesion to the endothelium. A response profile similar to the one of IL-6 was observed with a significant increase in IL-8 secretion only with the $25 \mu \mathrm{g} / \mathrm{ml}$ rhCRP stimulation (Fig. 3b). E2 pre-treatment at $10^{-8}$ and $10^{-9} \mathrm{M}$ for $1 \mathrm{~h}$ significantly reduced by up to $21 \%$ the impact of CRP on IL-8 production (Fig. 3d). E2 by itself, at the tested doses, had no effect on the basal level of ILs- 6 and -8 produced by the HAEC.

E2 reduces CRP-induced adhesion molecule upregulation

CRP is known to trigger adhesion molecule expression, such as VCAM-1 and ICAM-1 [19], involved in inflammatory cells' recruitment to endothelial lesion sites. After having observed the capacity of E2 to reduce CRP-induced IL-8 secretion, we evaluated if it could also reduce EC adhesion molecule expression induced by rhCRP. We first evaluated VCAM-1 and ICAM-1 total protein expression in HAECs after stimulation with increasing doses of detoxified rhCRP. Enhanced levels of these proteins were 


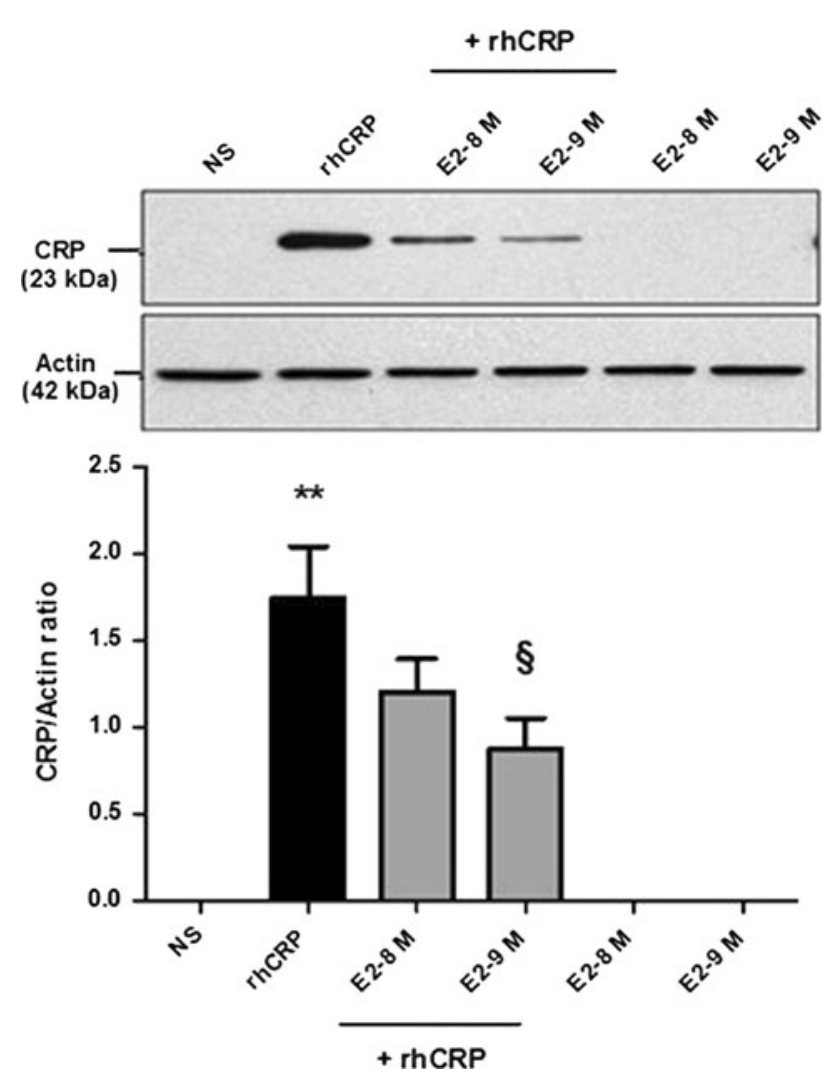

Fig. 2 CRP self-induction and negative regulation by E2 pretreatment. CRP protein expression was evaluated following a 1-h E2 pre-treatment $\left(10^{-8}\right.$ and $\left.10^{-9} \mathrm{M}\right)$ and a 24-h stimulation of rhCRP $(25 \mu \mathrm{g} / \mathrm{ml})$ either alone or in combination. CRP protein level was determined by western blot analysis and normalized to the level of $\beta$-actin protein. Data represents the mean \pm SEM $(N=8)$. $* * p<0.001$ versus not stimulated (NS); ${ }^{\S} p<0.01$ versus CRP

observed only with the highest dose of rhCRP $(25 \mu \mathrm{g} / \mathrm{ml})$ (Fig. 4a, b). This induction was comparable to the one obtained with $1 \mu \mathrm{g} / \mathrm{ml}$ of LPS derived from $E$. coli used as a positive control. Afterward, we investigated VCAM-1 and ICAM-1 protein expression following E2 and rhCRP treatments either alone or in combination. E2 alone had no effect on the expression levels of both adhesion molecules. However, the addition of E2 in pre-treatment $\left(10^{-8}\right.$ and $10^{-9} \mathrm{M}$ ) before the 24-h rhCRP stimulation decreased by $40 \%$ VCAM (Fig. 4c) and ICAM (Fig. 4d) protein levels with a significant reduction in the case of VCAM (Fig. 4c).

\section{E2 restores the HAECs' migration reduced by CRP}

As E2 modulates the pro-inflammatory responses induced by rhCRP and favors an anti-inflammatory pattern, we explored if E2 could improve impaired EC migration by CRP. By means of Transwell migration assays, we first demonstrated that cells stimulated with rhCRP at $25 \mu \mathrm{g} / \mathrm{ml}$ $(48.84 \pm 4.96 \%)$ for $24 \mathrm{~h}$ had a $51 \%$ reduction in their migratory capacity compared to basal condition (Fig. 5, black- vs. white bar). In contrast, cells exposed to E2 at $10^{-9} \mathrm{M}(153.12 \pm 9.77 \%)$ for $1 \mathrm{~h}$ demonstrated a $49 \%$ increase in migratory activity when compared to cells in media alone (Fig. 5, pale gray- vs. white bar). When added in pre-treatment, E2 $\left(10^{-9} \mathrm{M}\right)$ blocks the inhibitory effect of the rhCRP stimulation and restores the basal HAECs' migration response $(113.90 \pm 21.13 \%)$ to VEGF (Fig. 5, dark gray- vs. dark- vs. white bar).

NO has been reported to be central to the E2-mediated migration and pro-angiogenic activity as well as in the angiogenic response to VEGF [35]. To elucidate if it is through NO induction that E2 restore migration of CRPtreated EC, cells were treated with L-NAME, an inhibitor of NO synthase (NOS) enzyme. A L-NAME $\left(10^{-4} \mathrm{M}\right)$ treatment of $30 \mathrm{~min}$ was performed before exposure to E2 $(70.94 \pm 14.65 \%)$ to confirm the implication of NO in E2mediated pro-migratory effect toward VEGF. A $58 \%$ reduction in HAEC migration was observed compared to E2 treatment alone (Fig. 5, line- vs. pale gray bar). However, after rhCRP stimulation, L-NAME did not prevent the positive effect of E2 on the VEGF-mediated migratory response of CRP-exposed HAEC (127.76 $\pm 25.03 \%)$ (Fig. 5, scared- vs. dark gray bar). Therefore, these data suggest that NO is not the mechanism by which E2 counteract the inhibition effect of CRP on VEGF-mediated EC migration. The percentage corresponds to the cell count of each condition compared to the average cell count of unstimulated cells.

Induction of VEGF and VEGFR-2 is not part of E2-mediated migration of CRP-treated EC

E2 proangiogenic potential is also related to the induction of VEGF production by cells and lead to increased expression of VEGFR-2, an important receptor of the angiogenic mechanism reduces by CRP [36]. To evaluate the involvement of this growth factor in E2-mediated restoration of EC migration altered by CRP, secreted VEGF was measured in cell supernatants by ELISA. Also, VEGFR-2 expression at the cell surface was determined by flow cytometry. However, after treatment with E2 and rhCRP, alone or combined, no significant modulation of both parameters by either E2 or rhCRP was observed (Fig. 6).

\section{Discussion}

It is well accepted that CRP is an important risk factor for CVD playing a critical role in atherogenesis [37-39]. Originally, amplification of CRP production was attributable only to the liver with subsequent deposition of this protein at the inflammatory sites. Its endogenous 
Fig. 3 Cytokines (ILs-6 and -8) secreted by HAEC. ILs- 6 and -8 secretion was evaluated in the supernatant of HAEC stimulated with increasing concentration of rhCRP for $24 \mathrm{~h}$, a 1-h E2 pre-treatment $\left(10^{-8}\right.$ and $\left.10^{-9} \mathrm{M}\right)$ or both combined. ILs-6 level $(\mathbf{a}, \mathbf{c})$ and -8 level $(\mathbf{b}, \mathbf{d})$ was determined in culture supernatants by ELISA. Data represents the mean \pm SEM. $N=5$ (a), $N=4$ (b), $N=3$ (c), $N=5$ (d). ${ }^{* *} p<0.001$ versus CRP $25 \mu \mathrm{g} / \mathrm{ml}(\mathbf{a}, \mathbf{b})$; $* * p<0.001$ versus NS; ${ }_{p} p<0.01$ versus CRP $(\mathbf{c})$. $* * p<0.001$ versus NS; ${ }^{\S} p<0.05$ versus CRP (d)
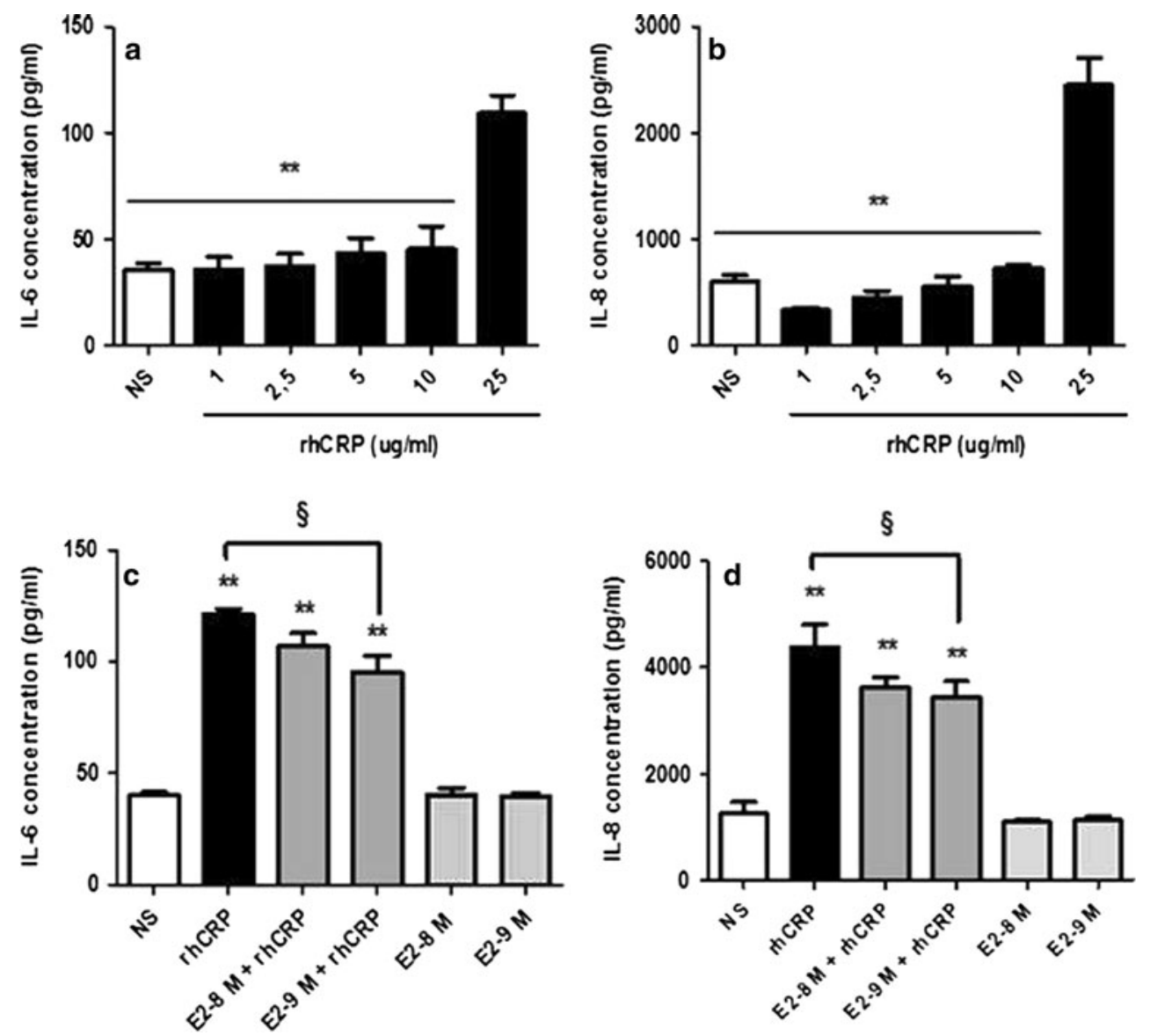

extrahepatic production by intimal vascular cells was first demonstrated by Yasojima et al. [40]. Then, the cytokine IL-6 was identified as the most important agonist of CRP production that regulates its transcriptional induction in both the HAEC and the liver [16]. Therefore, vascular EC can produce the CRP and the IL-6 contributing to their rapid increased concentration through a retroactive loop at the vascular injured sites [41, 42].

In the present study, purified rhCRP sodium azide and endotoxin free, responsible of reported experimental artefacts [43], was used to evaluate CRP self-induction in vascular EC. A dose dependent increase in self-induced protein expression was observed following stimulation of HAEC with rhCRP. The most significant effect occurred with the highest CRP dose $(25 \mu \mathrm{g} / \mathrm{ml})$, a concentration which could be representative of the exponential augmentation caused by a positive feedback on its own expression. Indeed, a 2.5-fold increase in CRP-stimulating dose from 10 to $25 \mu \mathrm{g} / \mathrm{ml}$ causes a fivefold increase in total CRP level $24 \mathrm{~h}$ later, an argument against the possibility that this increase could be simple due to the adhesion and/or uptake of the stimulating protein by cells. Equivalent doses of CRP in plasma represent a very high risk of CVD. However, its concentration in vascular lesion sites can be much greater than in serum. In atherosclerotic plaques, CRP level has been reported to be ten times higher than in a normal artery and seven times superior, as in the liver [40]. Our observations are the first suggesting a CRP synthesis that results from an endogenous autocrine/paracrine loop generated by EC.

The cardioprotective effect of E2 was questioned following the publication of various studies which have tested in vivo hormonal replacement therapy (HRT) [44, 45]. Controversial results showed an increase of hsCRP with the use of HRT in post-menopausal women [46]. Several factors may explain such conflicting results including drug composition (estrogen alone or combined with progesterone), concentration, treatment time, and route of administration. Some of these studies used relatively high concentration of E2, which may result in the development of complications [47]. As so, transdermal E2 did not trigger an increase in plasmatic CRP level compared to the oral formulation, suggesting a first passage effect in the liver [48]. In an animal study, E2 administered subcutaneously to transgenic mice expressing human CRP abolished the overexpression of CRP in the intima following a ligation of a coronary artery. It also reduced vascular inflammation, despite a stable blood level of CRP [49]. Therefore, a targeted delivery of the hormone may play a distinct role and have a beneficial effect for the prevention of 
Fig. 4 VCAM-1 and ICAM-1 total protein expression in HAEC. VCAM-1 and ICAM-1 protein expression was evaluated in HAEC after stimulation with increasing concentrations of rhCRP for $24 \mathrm{~h}$, a 1-h E2 pre-treatment $\left(10^{-8}\right.$ and $\left.10^{-9} \mathrm{M}\right)$ alone or in combination. VCAM-1 (a, c) and ICAM-1 (b, d) protein level was analyzed in cell lysate by western blot and normalized to the level of $\beta$-actin protein. Data represents the mean \pm SEM. $N=2$ (a), $N=2$ (b), $N=4$ (c), $N=4$ (d). $* * * p<0.001$, $* * p<0.01, * p<0.05$ versus $\mathrm{NS} ;{ }^{\S} p<0.05$ (c). $* * * p<0.001, * * p<0.01$ versus NS (d)
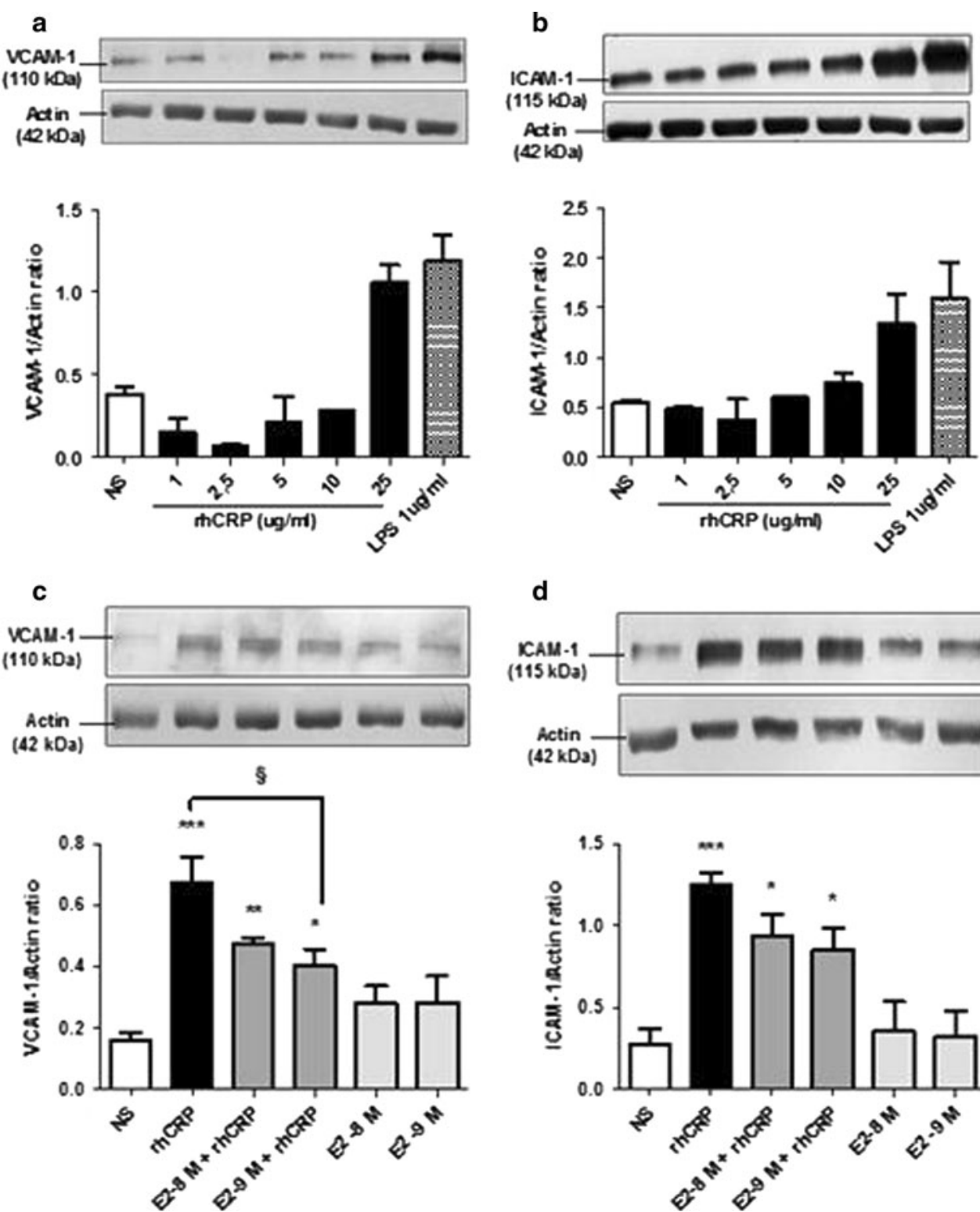

d
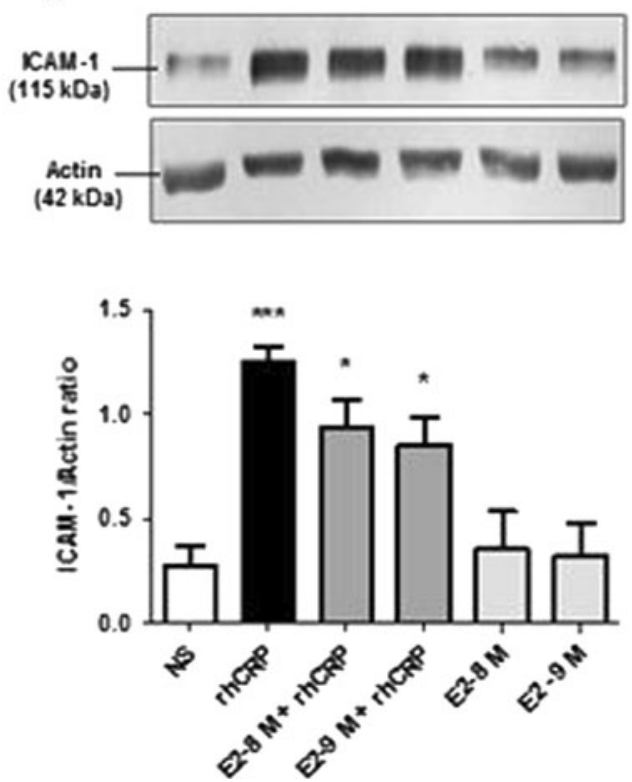

atherosclerosis. Our results show that, effectively, a pretreatment of E2 for $1 \mathrm{~h}$ at doses equivalent to its supraphysiologic and physiologic concentration $\left(10^{-8}\right.$ and $\left.10^{-9} \mathrm{M}\right)$ reduces CRP self-induction mechanism dose dependently. These results reveal that E2 attenuates the CRP expression by a rapid non-genomic effect, reflecting another beneficial mechanism of E2 mediated through this pathway.

Having demonstrated that E2 reduced the self-induction of CRP, we confirmed the elevation of IL- 6 production by EC with CRP treatment at a dose of $25 \mu \mathrm{g} / \mathrm{ml}$ of rhCRP. Our results are consistent with those of Verma et al. [41] which showed a similar elevation in IL-6 level following addition of a comparable dose of CRP to human saphenous vein ECs. E2 reduces vascular inflammation by altering the expression of adhesion molecules, chemokines, and pro-inflammatory cytokines [26, 33] such as IL-6, in part, through the negative regulation of the transcription factor NF- $\mathrm{KB}$. This factor is also involved in controlling the production of CRP by EC [26, 33, 50, 51]. With the partial inhibition of CRP self-induction and CRP-stimulated IL-6 production, we have shown that E2 could imply a direct inhibition of NF- $\mathrm{KB}$ activation and/or an indirect negative effect on IL-6 secretion, interfering with the amplification of CRP production. Likewise, IL-6 acts as a multifunctional cytokine by modulating the hepatic response and participating actively in the inflammatory process of atherogenesis. Indeed, this molecule is produced by multiple cell types present in the atheromatous plaque as EC and is strongly involved in the initiation and maintenance of inflammation, at least in part, by producing CRP [42]. Clinically, the reduction of CRP-induced IL-6 production 
Fig. 5 E2 restores the migratory response of CRPstimulated HAEC to VEGF. HAEC migration toward VEGF $(20 \mathrm{ng} / \mathrm{ml})$ was determined in Transwell chamber following E2 1 -h pre-treatment $\left(10^{-9} \mathrm{M}\right)$ and a 24-h stimulation with rhCRP $(25 \mu \mathrm{g} / \mathrm{ml})$ alone or in combination. L-NAME $\left(10^{-4} \mathrm{M}\right)$ was added $30 \mathrm{~min}$ before E2 treatment. L-NAME was also added to both the upper and lower compartment in control wells. HAEC migration is shown as a percentage of VEGF-induced increased compared to the average of unstimulated cells in basal condition. Data represents the mean $\pm \operatorname{SEM}(N=3)$. ${ }^{*} p<0.05$ versus NS; ${ }^{\S} p<0.05$ versus CRP; ${ }^{\S} p<0.01$ versus CRP; ${ }^{\star} p<0.01$ versus E2
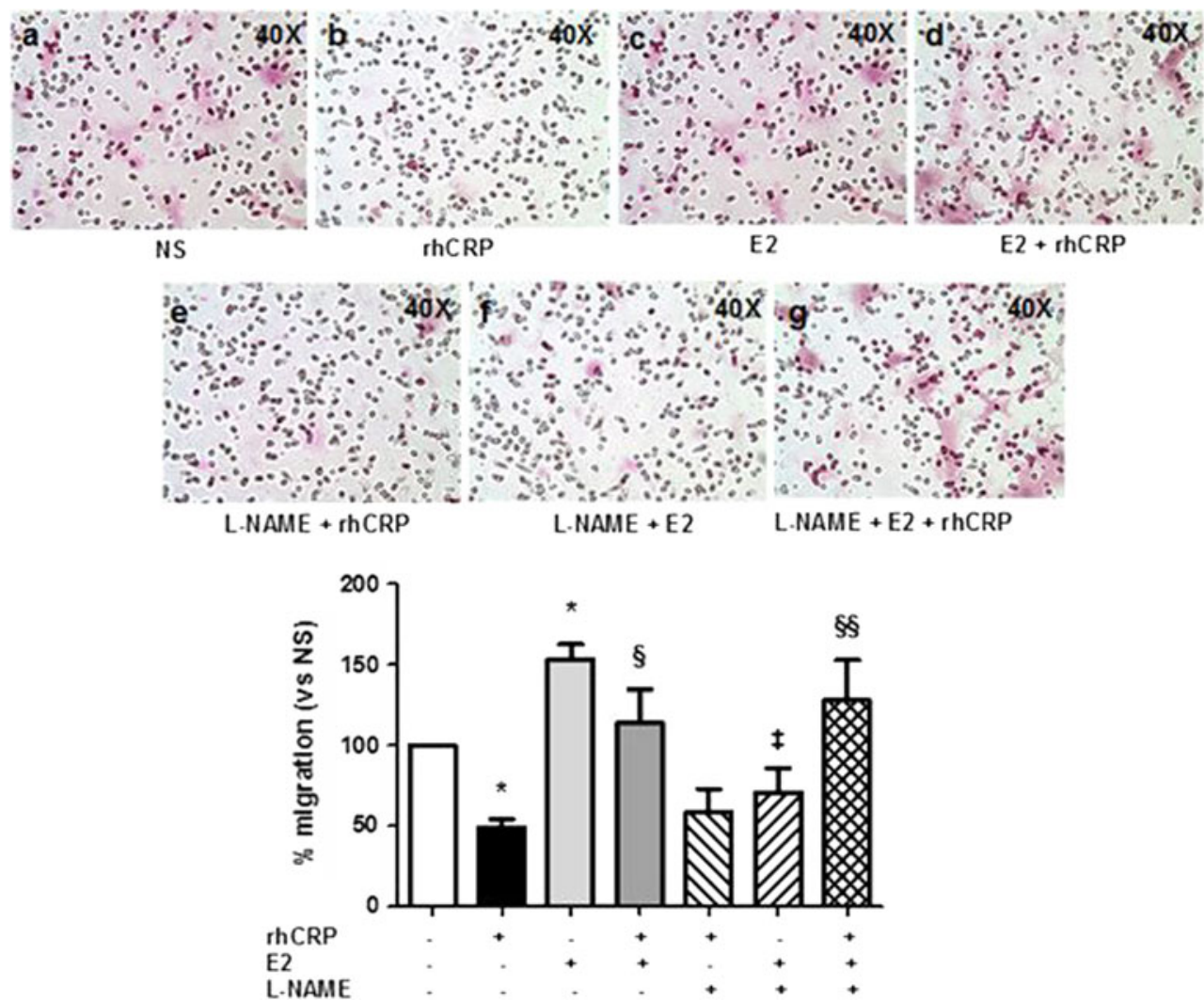

with E2 pre-treatment shown by our result could indicate a key role of this hormone in the prevention or reduction of cytokine inflammatory response implicated in the development and maintenance of atherosclerosis. An important step in atherosclerosis development is the recruitment of leukocytes in the vascular wall where they become foam cells. This inflammatory stage is favored by an augmentation of chemokine secretion, including IL-8 and MCP-1, and in adhesion molecules expression (ICAM-1, VCAM-1, and E-selectin) at the endothelium [52]. Besides, a substantial enhancement of CRP production in sites of atheromatous lesions further increases expression of proinflammatory molecules by EC [19-21]. The important upregulation of ILs-6, -8, ICAM-1, and VCAM-1 expression by HAEC was observed with the $25 \mu \mathrm{g} / \mathrm{ml}$ dose of rhCRP but not the lower dose of $10 \mu \mathrm{g} / \mathrm{ml}$. This corroborates with the effective dose reported by Devaraj et al. [19, 20]. Another team has demonstrated an ICAM and VCAM induction in human EC with $10 \mu \mathrm{g} / \mathrm{ml}$ CRP and even a lower dose [21], a level of activity that we do not observe with our highly purified rhCRP.

The well-recognized anti-inflammatory activity of E2 could counteract some of the pro-atherogenic activity of the CRP. Indeed, this hormone at $10^{-8}$ and $10^{-9} \mathrm{M}$ was shown to inhibit leukocyte migration and adhesion by blocking IL-8 secretion in human umbilical vein EC (HUVEC) [53]. E2 was also shown to attenuate monocytes recruitment to HAEC in response to TNF- $\alpha$ [34]. For the first time, we report that an E2 pre-treatment prevents partial HAEC inflammatory response to rhCRP. In fact, it results in a decreased IL- 8 secretion and a reduced VCAM1 and ICAM-1 protein expression, events that could reduce leukocytes recruitment induced by the CRP.

Vascular repair is as important as the reduction of inflammation to prevent progression of atherogenesis process. To allow arterial injury healing, regeneration of a healthy endothelium is essential to restore control of vascular tone, homeostasis as well as anticoagulant, antiaggregating, and anti-inflammatory properties [54]. Reendothelialization and angiogenesis necessary for endothelium reconstitution involves EC proliferation and migration. However, some evidence suggests that CRP may inhibit these cellular functions [55]. In accordance to these data, a recent article demonstrated that long-term exposure to this plasmatic protein significantly inhibited VEGF-induced migration of HUVEC [24]. In our experimental setting, we observed that a 24-h exposition of HAEC to rhCRP was sufficient to reduce their migration response to VEGF by more than $50 \%$. On the other hand, E2 has the ability to facilitate vascular repair. Effectively, we previously have demonstrated an improved reendothelialization and vascular healing process after local delivery of E2 at the site of vascular injury [31, 56]. We have also shown the induction of EC proliferation and 

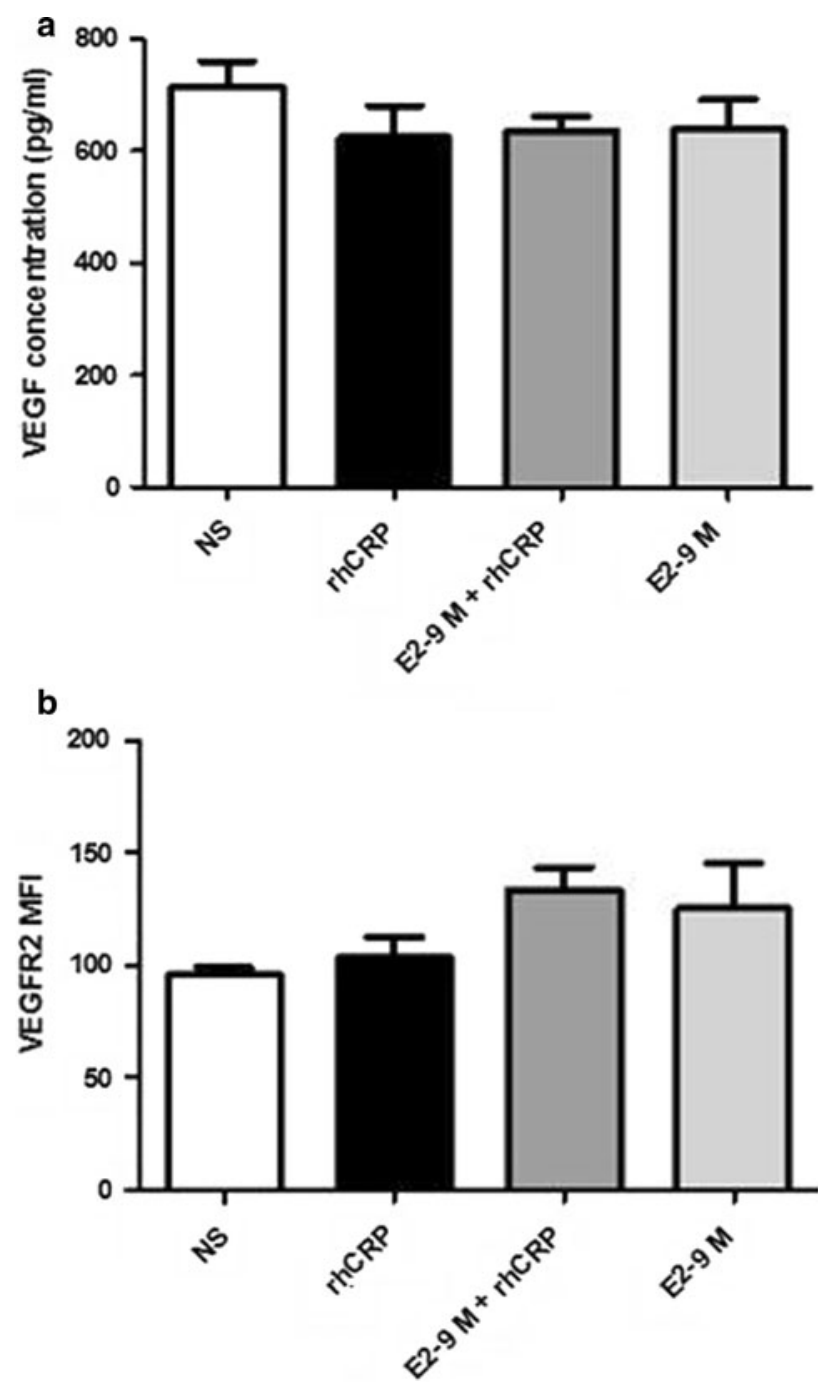

Fig. 6 VEGF secretion and VEGFR-2 expression by HAEC. VEGF secretion and VEGFR-2 expression was determined after HAEC's stimulation with a $24 \mathrm{~h}$ rhCRP $(25 \mu \mathrm{g} / \mathrm{ml})$ treatment and a $1 \mathrm{~h}$ E2 pretreatment $\left(10^{-8}\right.$ and $\left.10^{-9} \mathrm{M}\right)$ alone or in combination. VEGF was measured by ELISA in culture supernatants of HAEC (a). Cell surface VEGFR-2 expression was evaluated by flow cytometry and data are presented as MFI values (b). Data represent the mean \pm SEM. $N=3(\mathbf{a}, \mathbf{b})$

migration by this hormone via the activation of the estrogen receptor- $\alpha$ and the induction of p38 MAPK and ERK1/ 2 pathways [57]. In the current study, we demonstrated for the first time that E2 overcomes an important anti-angiogenic effect of the CRP and restores HAEC response to VEGF. A major pro-inflammatory and anti-angiogenic activity of CRP consists to downregulate endothelial NOS expression which decreases NO production by EC [18]. Inversely, E2 is known to promote the production of this important vasodilator associated to its non-genomic activation pathway [30]. NO plays an important role in EC functions including VEGF-mediated migration response [35]. First, we confirmed the role of NO in the pro- migratory effect of E2 using a NOS enzyme inhibitor (L-NAME) and observed a significant reduction of EC migration compared to E2 treatment alone. Interestingly, although this supports $\mathrm{NO}$ production as the mediator of $\mathrm{E} 2$ effect on EC, the enhanced migratory activity attributed to the E2 pre-treatment of CRP-stimulated EC was insensitive to this NO inhibition. Indeed, using L-NAME, E2 maintained its capacity to counteract the effects of CRP. This suggests that, in the presence of CRP, E2 counteracts the negative effects of this inflammatory protein on EC migration by another mechanism. E2 can inhibit the inflammatory response of CRP by a non-genomic pathway and ERK1/2 may be another cellular signaling target. Indeed, this cellular pathway is known to induce VEGF migration and to be modulated either by CRP and E2 $[24,58]$. Therefore, ERK1/2 could be a part of the mechanism for E2 in restoring EC migration impaired by CRP.

To identify the $\mathrm{E} 2$ mechanism of action, we investigated the expression of VEGFR-2, a receptor which controls mitogenic action of VEGF. This receptor was reported to be downregulated in EC by CRP. However, in our experimental setting, no difference in the expression of VEGFR-2 or of its ligand was observed following a CRP treatment. Nevertheless, the decrease in VEGFR-2 expression by CRP was only demonstrated at the mRNA level by Yang et al. [36]. On its side, E2 was reported to upregulate VEGFR-2 expression in microvasculature EC after a long-term treatment, showing a more likely involvement of the E2 genomic pathway or a paracrine effect [59]. Indeed, E2 was reported to promote VEGF production which then was responsible to trigger an increased expression of VEGFR-2 and pro-angiogenic activity by a paracrine mechanism $[59,60]$. In our experimental setting involving an E2 treatment of $24 \mathrm{~h}$ or less of human EC derived from the aortic artery, no induction of VEGF and VEGFR-2 protein level was detected. Altogether, these results point toward a mechanism other than improved NO availability or induced VEGFR-2 expression and VEGF secretion to explain E2 capacity to counteract the effects of CRP on EC.

\section{Conclusion}

Thus, in this study, we demonstrate that EC could express CRP and be a site for CRP self-induction. We illustrate a process of positive feedback production of the protein by vascular cells that could lead to the marked local increase concentration reported in atherosclerotic plaques. Furthermore, the present study highlights a novel vasoprotective role of E2 in the inhibition of this endogenous CRP selfinduction, altering its pro-inflammatory activities in vascular EC by a non-genomic pathway. By exploring the 
angiogenic potential of E2, our study demonstrates for the first time that this hormone restores EC migration altered by CRP. Further investigation will be needed to clarify mechanisms of E2 vascular protection by negative regulation of important proatherogenic inflammatory pathways controlled by CRP.

Acknowledgments This project was supported financially by the Grants from the Heart and Stroke Foundation of Canada (HSFC). We gratefully thank the Higher Education and Postdoctoral Faculty of the University of Montreal for the Excellence Award and Redaction Grant for 2010-2011. We also thank the Faculty of Medicine of the University of Montreal for the master degree scholarship of 2009-2010. Dr. Jean-François Tanguay is also supported by Fondation de l'Institut de Cardiologie de Montréal and réseau TheCell (FRSQ).

Conflict of interest None of the authors has competing financial interest to declare.

Open Access This article is distributed under the terms of the Creative Commons Attribution License which permits any use, distribution, and reproduction in any medium, provided the original author(s) and the source are credited.

\section{References}

1. Lusis AJ (2000) Atherosclerosis. Nature 407:233-241

2. Mullenix PS, Andersen CA, Starnes BW (2005) Atherosclerosis as inflammation. Ann Vasc Surg 19:130-138

3. Lavie CJ, Milani RV, Ventura HO (2009) Obesity and cardiovascular disease: risk factor, paradox, and impact of weight loss. J Am Coll Cardiol 53:1925-1932

4. Karavidas A, Lazaros G, Tsiachris D, Pyrgakis V (2010) Aging and the cardiovascular system. Hell J Cardiol 51:421-427

5. Beckman JA, Creager MA, Libby P (2002) Diabetes and atherosclerosis: epidemiology, pathophysiology, and management. JAMA 287:2570-2581

6. Reriani MK, Lerman LO, Lerman A (2010) Endothelial function as a functional expression of cardiovascular risk factors. Biomark Med 4:351-360

7. Koenig W (2007) Cardiovascular biomarkers: added value with an integrated approach? Circulation 116:3-5

8. Ridker PM (2001) High-sensitivity C-reactive protein: potential adjunct for global risk assessment in the primary prevention of cardiovascular disease. Circulation 103:1813-1818

9. Pepys MB, Hirschfield GM (2003) C-reactive protein: a critical update. J Clin Investig 111:1805-1812

10. Berk BC, Weintraub WS, Alexander RW (1990) Elevation of C-reactive protein in "active" coronary artery disease. Am J Cardiol 65:168-172

11. Liuzzo G, Biasucci LM, Gallimore JR, Grillo RL, Rebuzzi AG, Pepys MB, Maseri A (1994) The prognostic value of C-reactive protein and serum amyloid a protein in severe unstable angina. N Engl J Med 331:417-424

12. Devaraj S, Singh U, Jialal I (2009) The evolving role of C-reactive protein in atherothrombosis. Clin Chem 55:229-238

13. Zhang YX, Cliff WJ, Schoefl GI, Higgins G (1999) Coronary C-reactive protein distribution: its relation to development of atherosclerosis. Atherosclerosis 145:375-379

14. Calabro P, Willerson JT, Yeh ET (2003) Inflammatory cytokines stimulated C-reactive protein production by human coronary artery smooth muscle cells. Circulation 108:1930-1932
15. Ciubotaru I, Potempa LA, Wander RC (2005) Production of modified C-reactive protein in U937-derived macrophages. Exp Biol Med (Maywood) 230:762-770

16. Venugopal SK, Devaraj S, Jialal I (2005) Macrophage conditioned medium induces the expression of $\mathrm{C}$-reactive protein in human aortic endothelial cells: potential for paracrine/autocrine effects. Am J Pathol 166:1265-1271

17. Verma S, Szmitko PE, Ridker PM (2005) C-reactive protein comes of age. Nat Clin Pract Cardiovasc Med 2:29-36 (quiz 58)

18. Venugopal SK, Devaraj S, Yuhanna I, Shaul P, Jialal I (2002) Demonstration that C-reactive protein decreases eNOS expression and bioactivity in human aortic endothelial cells. Circulation 106:1439-1441

19. Pasceri V, Willerson JT, Yeh ET (2000) Direct proinflammatory effect of C-reactive protein on human endothelial cells. Circulation 102:2165-2168

20. Devaraj S, Kumaresan PR, Jialal I (2004) Effect of C-reactive protein on chemokine expression in human aortic endothelial cells. J Mol Cell Cardiol 36:405-410

21. Devaraj S, Davis B, Simon SI, Jialal I (2006) CRP promotes monocyte-endothelial cell adhesion via Fcgamma receptors in human aortic endothelial cells under static and shear flow conditions. Am J Physiol Heart Circ Physiol 291:H1170H1176

22. Fu T, Borensztajn J (2002) Macrophage uptake of low-density lipoprotein bound to aggregated C-reactive protein: possible mechanism of foam-cell formation in atherosclerotic lesions. Biochem J 366:195-201

23. Cirillo P, Golino P, Calabro P, Cali G, Ragni M, De Rosa S, Cimmino G, Pacileo M, De Palma R, Forte L, Gargiulo A, Corigliano FG, Angri V, Spagnuolo R, Nitsch L, Chiariello M (2005) C-reactive protein induces tissue factor expression and promotes smooth muscle and endothelial cell proliferation. Cardiovasc Res 68:47-55

24. Schneeweis C, Grafe M, Bungenstock A, Spencer-Hansch C, Fleck E, Goetze S (2010) Chronic CRP-exposure inhibits VEGFinduced endothelial cell migration. J Atheroscler Thromb 17:203-212

25. Barrett-Connor E (1997) Sex differences in coronary heart disease. Why are women so superior? The 1995 Ancel Keys Lecture. Circulation 95:252-264

26. Xing D, Nozell S, Chen YF, Hage F, Oparil S (2009) Estrogen and mechanisms of vascular protection. Arterioscler Thromb Vasc Biol 29:289-295

27. Czubryt MP, Espira L, Lamoureux L, Abrenica B (2006) The role of sex in cardiac function and disease. Can J Physiol Pharmacol 84:93-109

28. Baker L, Meldrum KK, Wang M, Sankula R, Vanam R, Raiesdana A, Tsai B, Hile K, Brown JW, Meldrum DR (2003) The role of estrogen in cardiovascular disease. J Surg Res 115:325-344

29. Mendelsohn ME, Karas RH (1999) The protective effects of estrogen on the cardiovascular system. $N$ Engl $J$ Med 340:1801-1811

30. Chen Z, Yuhanna IS, Galcheva-Gargova Z, Karas RH, Mendelsohn ME, Shaul PW (1999) Estrogen receptor alpha mediates the nongenomic activation of endothelial nitric oxide synthase by estrogen. J Clin Investig 103:401-406

31. Chandrasekar B, Sirois MG, Geoffroy P, Lauzier D, Nattel S, Tanguay JF (2005) Local delivery of 17beta-estradiol improves reendothelialization and decreases inflammation after coronary stenting in a porcine model. Thromb Haemost 94:1042-1047

32. Tanguay JF (2005) Vascular healing after stenting: the role of 17-beta-estradiol in improving re-endothelialization and reducing restenosis. Can J Cardiol 21:1025-1030

33. Straub RH (2007) The complex role of estrogens in inflammation. Endocr Rev 28:521-574 
34. Mikkola TS, St Clair RW (2002) Estradiol reduces basal and cytokine induced monocyte adhesion to endothelial cells. Maturitas 41:313-319

35. Papapetropoulos A, Garcia-Cardena G, Madri JA, Sessa WC (1997) Nitric oxide production contributes to the angiogenic properties of vascular endothelial growth factor in human endothelial cells. J Clin Investig 100:3131-3139

36. Yang H, Nan B, Yan S, Li M, Yao Q, Chen C (2005) C-reactive protein decreases expression of VEGF receptors and neuropilins and inhibits VEGF165-induced cell proliferation in human endothelial cells. Biochem Biophys Res Commun 333:1003-1010

37. Ridker PM, Rifai N, Rose L, Buring JE, Cook NR (2002) Comparison of C-reactive protein and low-density lipoprotein cholesterol levels in the prediction of first cardiovascular events. N Engl J Med 347:1557-1565

38. Koenig W, Sund M, Frohlich M, Fischer HG, Lowel H, Doring A, Hutchinson WL, Pepys MB (1999) C-reactive protein, a sensitive marker of inflammation, predicts future risk of coronary heart disease in initially healthy middle-aged men: results from the MONICA (Monitoring Trends and Determinants in Cardiovascular Disease) Augsburg Cohort Study, 1984 to 1992. Circulation 99:237-242

39. Kuller LH, Tracy RP, Shaten J, Meilahn EN (1996) Relation of C-reactive protein and coronary heart disease in the MRFIT nested case-control study. Multiple Risk Factor Intervention Trial. Am J Epidemiol 144:537-547

40. Yasojima K, Schwab C, McGeer EG, McGeer PL (2001) Generation of $\mathrm{C}$-reactive protein and complement components in atherosclerotic plaques. Am J Pathol 158:1039-1051

41. Verma S, Li SH, Badiwala MV, Weisel RD, Fedak PW, Li RK, Dhillon B, Mickle DA (2002) Endothelin antagonism and interleukin-6 inhibition attenuate the proatherogenic effects of C-reactive protein. Circulation 105:1890-1896

42. Ferri C, Croce G, Cofini V, De Berardinis G, Grassi D, Casale R, Properzi G, Desideri G (2007) C-reactive protein: interaction with the vascular endothelium and possible role in human atherosclerosis. Curr Pharm Des 13:1631-1645

43. Taylor KE, Giddings JC, van den Berg CW (2005) C-reactive protein-induced in vitro endothelial cell activation is an artefact caused by azide and lipopolysaccharide. Arterioscler Thromb Vasc Biol 25:1225-1230

44. Grady D, Wenger NK, Herrington D, Khan S, Furberg C, Hunninghake D, Vittinghoff E, Hulley S (2000) Postmenopausal hormone therapy increases risk for venous thromboembolic disease. The heart and estrogen/progestin replacement study. Ann Intern Med 132:689-696

45. Stampfer MJ, Colditz GA, Willett WC, Manson JE, Rosner B, Speizer FE, Hennekens CH (1991) Postmenopausal estrogen therapy and cardiovascular disease. Ten-year follow-up from the nurses' health study. N Engl J Med 325:756-762

46. Duvernoy C (2003) Estrogen and C-reactive protein: does an alternate route lead to a more attractive destination? Thromb Haemost 90:1-2

47. Hsia J, Langer RD, Manson JE, Kuller L, Johnson KC, Hendrix SL, Pettinger M, Heckbert SR, Greep N, Crawford S, Eaton CB,
Kostis JB, Caralis P, Prentice R (2006) Conjugated equine estrogens and coronary heart disease: the Women's Health Initiative. Arch Intern Med 166:357-365

48. Lacut K, Oger E, Le Gal G, Blouch MT, Abgrall JF, Kerlan V, Scarabin PY, Mottier D (2003) Differential effects of oral and transdermal postmenopausal estrogen replacement therapies on C-reactive protein. Thromb Haemost 90:124-131

49. Wang D, Oparil S, Chen YF, McCrory MA, Skibinski GA, Feng W, Szalai AJ (2005) Estrogen treatment abrogates neointima formation in human C-reactive protein transgenic mice. Arterioscler Thromb Vasc Biol 25:2094-2099

50. Calabro P, Golia E, Yeh ET (2009) CRP and the risk of atherosclerotic events. Semin Immunopathol 31:79-94

51. Verma S, Badiwala MV, Weisel RD, Li SH, Wang CH, Fedak PW, Li RK, Mickle DA (2003) C-reactive protein activates the nuclear factor-kappaB signal transduction pathway in saphenous vein endothelial cells: implications for atherosclerosis and restenosis. J Thorac Cardiovasc Surg 126:1886-1891

52. Sullivan GW, Sarembock IJ, Linden J (2000) The role of inflammation in vascular diseases. J Leukoc Biol 67:591-602

53. Rodriguez E, Lopez R, Paez A, Masso F, Montano LF (2002) 17Beta-estradiol inhibits the adhesion of leukocytes in TNF-alpha stimulated human endothelial cells by blocking IL-8 and MCP-1 secretion, but not its transcription. Life Sci 71:2181-2193

54. Aird WC (2007) Phenotypic heterogeneity of the endothelium: I. Structure, function, and mechanisms. Circ Res 100:158-173

55. Schwartz R, Osborne-Lawrence S, Hahner L, Gibson LL, Gormley AK, Vongpatanasin W, Zhu W, Word RA, Seetharam D, Black S, Samols D, Mineo C, Shaul PW (2007) C-reactive protein downregulates endothelial NO synthase and attenuates reendothelialization in vivo in mice. Circ Res 100:1452-1459

56. Chandrasekar B, Nattel S, Tanguay JF (2001) Coronary artery endothelial protection after local delivery of 17beta-estradiol during balloon angioplasty in a porcine model: a potential new pharmacologic approach to improve endothelial function. J Am Coll Cardiol 38:1570-1576

57. Geraldes P, Sirois MG, Bernatchez PN, Tanguay JF (2002) Estrogen regulation of endothelial and smooth muscle cell migration and proliferation: role of p38 and p42/44 mitogenactivated protein kinase. Arterioscler Thromb Vasc Biol 22:1585-1590

58. Kibayashi E, Urakaze M, Kobashi C, Kishida M, Takata M, Sato A, Yamazaki K, Kobayashi M (2005) Inhibitory effect of pitavastatin (NK-104) on the C-reactive-protein-induced interleukin8 production in human aortic endothelial cells. Clin Sci (Lond) 108:515-521

59. Suzuma I, Mandai M, Takagi H, Suzuma K, Otani A, Oh H, Kobayashi K, Honda Y (1999) 17 Beta-estradiol increases VEGF receptor-2 and promotes DNA synthesis in retinal microvascular endothelial cells. Investig Ophthalmol Vis Sci 40:2122-2129

60. Herve MA, Meduri G, Petit FG, Domet TS, Lazennec G, Mourah S, Perrot-Applanat M (2006) Regulation of the vascular endothelial growth factor (VEGF) receptor Flk-1/KDR by estradiol through VEGF in uterus. J Endocrinol 188:91-99 